rev Psi

Revista de Psicología (UNLP)

https://revistas.unlp.edu.ar/revpsi

\title{
Lo singular en lo colectivo: lógica del dispositivo para el tratamiento del autismo
}

\author{
Gustavo Slatopolsky 1,2,3
}

Correspondencia

slatopo@gmail.com

\section{Filiaciones institucionales}

${ }^{1}$ la cigarra (Argentina)

${ }^{3}$ PAUSA/lalata (Argentina)

${ }^{2}$ Escuela de Orientación Lacaniana (EOL, Argentina)

\section{Resumen}

La idea del trabajo prosigue la vertiente de investigación abierta a partir del desafío que implicó en la cigarra poner a prueba el dispositivo y su eficacia en el trabajo en la web obligado por la pandemia. En términos generales es posible desagregar a modo expositivo cuatro lugares a relevar: (1) cómo concebimos lo "colectivo" si la apuesta es por lo singular; (2) la transferencia: lo singular en lo colectivo; (3) el lugar del acto en un dispositivo colectivo y la paradoja que ello implica; (4) la idea de un dispositivo maleable que pueda prestarse para hacer uso de él.

\section{Palabras clave}

autismo | psicoanálisis | dispositivo | colectivo

\section{Cómo citar}

Slatopolsky, G. (2021). Lo singular en lo colectivo: lógica del dispositivo para el tratamiento del autismo. Revista de

Psicología, 20(1), 98-107. HTTPs:// DX.DOI.ORG/10.24215/2422572XE121

\begin{tabular}{|c|c|}
\hline \multicolumn{2}{|c|}{ Proceso editorial } \\
\hline Recibido & 1ra decisión \\
\hline 30 may. 2021 & 12 jun. 2021 \\
\hline Aceptado & Publicado \\
\hline 12 jun. 2021 & 30 jul. 2021 \\
\hline
\end{tabular}

Coordinadora del dossier

María Cristina Piro (Facultad de Psicología UNLP, Argentina).
ISSN

2422-572X

Licencia

Licencia de Cultura Libre CC-BY 4.0

(Compartir - Adaptar - Atribuir)

Entidad editora

RevPsi es una publicación de la

Facultad de Psicología (Universidad

Nacional de La Plata, Argentina) 


\section{0 singular no coletivo: lógica do dispositivo para o tratamento do autismo}

\section{Resumo}

A idéia do trabalho continua o aspecto de pesquisa aberto a partir do desafio que implicava la cigarra de testar o dispositivo e sua eficácia no trabalho na rede forçada pela pandemia. Em termos gerais, é possível desagregar, de forma expositiva, quatro lugares a serem revelados: (1) como concebemos o "coletivo" se a aposta é no singular; (2) transferência: o singular no coletivo; (3) o lugar do ato em um dispositivo coletivo e o paradoxo que isso implica; (4) a idéia de um dispositivo maleável que pode ser emprestado para fazer uso dele.

\section{Palavras-chave}

autismo | psicoanálise | dispositivo | colectivo

\section{The singular in the collective: logic of the device for the treatment of autism}

\section{Abstract}

The work is based on the challenge that la cigarra faced in testing the device and its effectiveness in the online work forced by the pandemic. In general terms, it is possible to disaggregate, by way of exposition, four places to be explored: (1) how we conceive of the "collective" if the bet is on the singular; (2) transference: the singular in the collective; (3) the place of the act in a collective device and the paradox that this implies; (4) the idea of a malleable device that can be lent to make use of it.

\section{Keywords}

autism | psychoanalysis | device | collective 


\section{Lo colectivo y la apuesta por lo singular}

La modalidad propia que plantea la cigarra coloca desde el principio la necesidad de consentir una cesión. El hecho de que los talleres se instalen en una lógica "para todos" fuerza desde el vamos la producción de un objeto en el parlêtre a la medida de la propuesta del taller.

En el taller "punto y coma" por ejemplo, se recorre entre todos los participantes la deriva del armado de una oración en la que cada uno a su turno aporta la palabra que sigue y así la frase serpentea sentidos, se clava de repente, reanuda golpeada por una detención inesperada y alcanza una detención definitiva cuando algún participante decide colocar el punto final.

Desde ya, si el experimento en cuestión puede ser puesto en el origen a la cuenta de los surrealistas, su inmersión en la cigarra tiene un efecto cercano a la apuesta del ready-made de Duchamp: puesto a jugar en la cigarra el cadáver exquisito deviene artificio (Lacan, 1975/2005) que busca incidir en la posición del sujeto.

La propuesta de una palabra que sigue a otra hace entrar una inmersión obligada en la sintaxis y recrea una atmósfera de semántica abierta en la que la significación por venir se desprende de la voluntad de cada quien ya que aquello que la frase diga será consecuencia de la palabra que sigue y que corresponde al compañero que la continúa. Es a esta invitación a soportarse en una sintaxis, respetar el turno y secuenciar aquello por decir en función de cómo viene articulada la frase por los otros que la antecedieron, donde puede leerse la idea de tener que consentir en la producción de un objeto que es ya cesión de la posición cuando de lo que se trata es de autismo. Nada más a contrapelo a la lógica iterativa del autismo que proponerle "conversar" con el significante que le antecede y hacer lugar al que sigue. Sin detenerse a priori en la posición de cada quién, el taller en su movimiento mismo invita, fuerza, conmina de manera amigable a producir un objeto que se acople a la lógica orquestada por el juego para ser cedido a su turno, depositado en la cadena articulada por la sintaxis.

Si bien la viñeta que propondremos al trabajo corresponde a este taller, en todos y cada uno de los talleres en la cigarra se desprende una misma lógica: no se pone a disposición del niño o niña el dispositivo en pos de "seguirlo" en los rodeos para quedar articulados a una circulación infinita sino que, a la inversa, eso con lo que llega deberá hacerse parte de la atmósfera que trasunta el taller en su propuesta "para todos" para desde ahí dar lugar al acto que hace agujero (Laurent, 2012). Planteado de esta manera, se sigue que no hay taller sin lectura de la transferencia en juego y no hay acto sin recorte de lo singular en el marco colectivo (Slatopolsky, 2019). Se trata de espacios colectivos que fuerzan al síntoma a adentrarse en esa otra lógica que le propone el taller por quedar tomado el Uno de la iteración en la malla de la sintaxis y del significado, aunque más no sea por su rechazo a entrar cuando en su turno se lo convoca. Cuando en ausencia de síntoma y frente a la imposibilidad del recorte de una letra se le plantee al parlêtre la dificultad de orientarse en el murmullo de lalengua (Laurent, 2012) en una espacialidad sensoria no por ello menos lenguajera, el trabajo 
en lo colectivo se orientará en la producción de un recorte que oficie de límite.

\section{Lo singular en lo colectivo}

La paradoja en juego conlleva la invención de un taller para cada niño dentro de un mismo taller. A su manera, es como decir que cada uno juega su juego cuando juegan todos juntos y ello solo es posible a partir de ser leído en tanto que tal. De lo que se tratará en el taller no será de complemento alguno del análisis individual, menos aún de la producción imposible de algún orden sublimado. Por el contrario, el desafío es la invención de una trama capaz de acoger en un mismo devenir lo singular de cada uno para ponerlo en una circulación; cuando esto se torna posible transforma el taller en la condición desde la cual poder ir hacia el lazo. En este sentido aquello que llamamos taller no es otra cosa que una manera particular de hacer presente la condición para que haya del analista vez por vez.

En una frase que se venía hilvanando en el taller, una niña autista al ser convocada a decir la palabra dice de manera intempestiva el nombre de un personaje animado que oficia de borde (Laurent, 2012). Se podría decir que soportada en el borde que arma la imagen alcanza una enunciación que le permite responder a la demanda, pero aquello que la soporta y da asiento a la enunciación es, a la vez, la palabra con que responde en una circularidad al infinito. Es esa circularidad lo que irrumpe como aquello que Frances Tustin ubica como el lugar de cascarón protector (Tustin, 1992) y que encuentra otra lógica a partir de la idea de borde en Eric Laurent (Laurent, 2012).

Es claro que dicho personaje, o más bien su nombre (la palabra que usa en todo momento en toda escena que se le presenta, aún cuando cuenta con una sintaxis que si bien deficitaria le permite salir al paso para hablar cuando no queda tomada por esa palabra), al tiempo que localiza el goce del Otro fracasa en su función de articularse a alguna otra cosa. Es decir, esa imagen sostenida en una palabra ocupa un lugar crucial en la economía libidinal con estatuto de defensa pero aquello mismo que localiza, en este caso, la deja fuera del lazo. Allí queda precisada la dificultad: cómo conmover aquello que opera detención en el acceso a los otros si eso mismo es lo más propio y actualiza una defensa lograda; es decir, cuál sería una transformación posible que advertida de su lugar de solución habilite una nueva dirección. Más precisamente: desde qué modalidad de dispositivo hacer lugar al acto para que la defensa consolidada alcance función de agujero y delimite un campo posible en el sujeto (Slatopolsky, 2021).

Por tratarse precisamente de una lógica singular en la malla de lo colectivo será necesario un desarrollo más amplio que permita situar el instante en que el objeto de la niña impacta en la sintaxis articulada producida con anterioridad por sus compañeros, hecho que delimita condiciones propias a la gramática. Una manera de decir: no se puede escribir de cualquier manera.

Vayamos a la frase: allí donde otro niño autista suele responder con un objeto fijo que se reitera de manera idéntica (al igual que la niña en cuestión que analizaremos 
seguidamente), la posición defensiva del mismo queda conmovida al preguntarle, para dar comienzo a la frase, qué animal le causa temor: “¿qué te da mucho miedo?”. Su cuerpo se tensa; en lugar de repetir de inmediato con la palabra de siempre (con estatuto de objeto autístico que localiza un borde), responde por primera vez desde un cuerpo afectado con un significante que localiza un temor. El haber pasado por un instante de enunciación permite desacomodar la defensa sin por ello dar lugar a la mutilación en el sujeto. El objeto producido queda depositado en el espacio de la frase que la acoge para de inmediato hacer lugar al compañero que sigue, que debe anudar la palabra por venir. Las cucarachas será esa palabra; aquello a lo que el niño teme y ha quedado escrito en la hoja del coordinador dará comienzo a la frase y quedará a la espera de la palabra que sigue, que corresponderá al participante siguiente.

El estatuto del significante "las cucarachas" plantea diversas aristas: es instante abierto a la enunciación y objeto producido por efecto de dicha apertura; a la vez, localización de borde que hace agujero en el parlêtre y en ello mismo extensión del antiguo borde, que da apertura a afectos que lo afectan, ahora en la posibilidad de una enunciación mesurada; así también neo borde que se anota por fuera del régimen iterativo que hasta ese momento conminaba en el parlêtre a la reiteración del objeto anterior cada vez; por último, es con este objeto que el niño puede responder de manera articulada en un espacio con otros, en un campo de sentido y que incluye afectos. Esto último, de manera más simple: nombrar "las cucarachas" hace posible ahora entablar un diálogo con otros y responder a la demanda que se le hace desde el taller. Al hacerlo queda corrido por un instante de la perseveración a la que quedaba constreñido (y por ello mismo, a salvo) por esa Una sola palabra para todo servicio que, dicho sea paso, no es una sino unas pocas que se cuentan con los dedos de una mano pero todas circunscriptas en la modalidad lógica del goce del Uno en su iteración. Pero quizá la arista más importante provenga de la lógica a la que obliga el juego: esa palabra queda forzada a conversar con la que sigue.

De allí que podamos diferenciar la estructura intrínseca al juego por un lado -que tracciona al Uno para hacerlo hablar-, de la intervención que al convocar a niño preguntándole por sus miedos conmueve la defensa, pregunta a la que el juego no obliga y que lo recorta del conjunto. Este es el nudo fundamental: está la malla de la frase que entrama y está el decir encarnado en el coordinador que, en ese modo de dirigirse al niño transforma la demanda propia del juego "para todos" en acto singular que hace agujero y habilita la producción de una letra que localiza de manera inédita al sacudir la defensa de la buena manera. Establecidas así las coordenadas de lectura que establecen lo propio del juego y la convocatoria que lo singulariza, puede ahora inferirse que el resorte en el taller que hace posible la cesión es la dimensión transferencial que se sirve del juego para dar lugar al acto: se trata de la dimensión propiamente analítica que instala el dispositivo.

La viñeta ${ }^{1}$ :

La frase construída trabajosamente antes de convocar a la niña había llegado a escribir (Slatopolsky, 2021): 


\section{LAS CUCARACHAS - MIRAN LA TELE - CON LOS OJOS - ABIERTOS}

Las palabras separadas por guiones establecen lugares; cada uno de estos lugares recibe el texto del niño o niña a quién se le demanda su palabra para proseguir. Se puede leer sin dificultad que sólo al primero se le ha preguntado por el miedo y que aquellos que lo siguen aportan trabajosamente su palabra sin que nadie pueda saber a priori adonde llevará la significación. Las palabras que siguen tienen la función de no dejar el S1 producido suelto ni, si por caso se tratase de significante en lo real que irrumpiese como certeza (Lacan, 1958/1987), con una eventual significación fija atada a la intrusión. La significación abierta enlaza lo que habla solo produciendo significado y transforma el sentido cuando irrumpe fija la persecución. Ambas posibilidades se abren por el solo hecho de tomar la progresión que habilita la dimensión diacrónica de la cadena significante al hacer lugar al factor tiempo en su producción.

Las cucarachas habían encontrado un sentido inquietante pero delimitado cuando toca el turno de la niña en cuestión. Se le pide su palabra y responde "Bob Esponja". Esa palabra, en boca de la niña, es jaculatoria; presta a irrumpir en todo tiempo y lugar, con o sin demanda. En ocasiones anteriores, esta misma palabra ha sido aceptada y colocada en frases en el lugar de "su" palabra. Pero ahora, con esta frase, en lugar de tomar lo que dice se la confronta por primera vez con el hecho de que en una lectura concatenada esa palabra hace explotar el significado por no soportarse en la sintaxis. Dicha palabra, vale la pena subrayarlo, irrumpe como jaculatoria que sacude el cuerpo de la niña en una dimensión fónica que trasunta la ausencia de la extracción de la voz (Maleval, 2009). Cuando esto irrumpe, su cuerpo se desacomoda como sacudido por eso que acaba de exclamar. Decimos "palabra" porque es eso lo que le pedimos cuando se la convoca pero es claro que eso que escupe es un objeto de imposible extracción que mutila el cuerpo (Maleval, 2009) y que tiene estatuto de emisión de cuerpo (Laurent,2012), aún cuando se trate de un intento que fracasa en su localización en el significante.

Se le vuelve a leer la frase en voz alta para intentar hacer lugar a otra palabra que pueda enlazarse a la significación y la insistencia en la niña en colocar allí el objeto fijo hace obstáculo al lazo. Cuando por tercera vez irrumpe por toda respuesta "Bob Esponja", se sanciona que su palabra "queda vacía". A las palabras de sus compañeros se le suma ahora, en el lugar que se le reserva, un recuadro dibujado sin nada en su interior: falta la palabra, queda vacío.

De inmediato el coordinador acerca su cuaderno a la computadora para que ella pueda ver la frase escrita y "su lugar", vacío. El efecto que esto le produce es impactante. Su cuerpo se aquieta al instante; se acerca concentrada al recuadro en la computadora del coordinador para observar ese recuadro vacío escrito de un modo calmo; ahora mira de manera recortada ese recuadro en un aire perplejidad que no empuja respuesta alguna.

La frase se continúa con las frases de otros compañeros, siempre preservando ese casillero vacío que se lee en voz alta cada vez que se pasa por allí. Así, en otro 
momento, al encontrarse el coordinador leyendo en voz alta: "Las cucarachas miran la tele con los ojos abiertos queda vacío" es interrumpido por la niña que grita su nombre (Cicchetti, 2021; Seijas, 2021): queda vacío---------su nombre.

\section{El acto, lo colectivo, la paradoja}

Decimos al comienzo que es necesario un deshacimiento del carácter "para todos" en el taller para que pueda tener lugar el acto y con ello el psicoanálisis pueda hacerse presente sostenido en la transferencia. Es preciso el instante en que alguno de los participantes del taller se sienta llamado a interpretar cortocircuitando el imaginario de lo colectivo en dirección a un-solo-niño en una palabra única que se le dirige y que no forma parte de las reglas del juego. Cuando esa palabra alcanza el sujeto, el acto es sancionado en la producción de una letra inédita que hace de la intervención un instante propiamente analítico: hubo del analista a partir de los efectos y es a partir de esa consecuencia que el lazo del niño con quien encarna ese lugar alcanza un investimento en el que nada será lo mismo a partir de entonces; se trata un antes y un después.

Sería imposible la intervención sin el sostén que delimitan los lugares en la frase del taller en cuestión. De hecho, es en el devenir del juego que se abre la posibilidad de la intervención. La misma puede ser escandida en tiempos articulados a los fines de una mejor exposición y lectura:

- Decir que no, a partir de un tiempo cero que es haber consentido siempre su Bob Esponja en cualquier lugar de la frase, sin ninguna articulación a la significación articulada.

- Insistir en el reconocimiento de su lugar de sujeto, su dignidad, en la invitación y la espera de una palabra nueva que no adviene.

- Instante de la sorpresa, en la que luego de alojar siempre el objeto se busca hacer lugar al sujeto forzando una cesión del mismo en la negativa a anotar la iteración. Es importante diferenciar aquí la negativa a acogerlo del rechazo. En la negativa se sostiene el lugar sujeto y resuena el llamado.

- Del acto solo se sabe a partir de los efectos; una manera de decir que solo por sus efectos una intervención alcanza su estatuto de acto.

- La respuesta del sujeto en dos tiempos:

- El aquietamiento del cuerpo en la cesión de la mirada que le permite localizar en el punto de vacío imaginarizado en el recuadro de la frase el efecto agujero. El acto localiza un borde que la separa del goce del Otro.

- En el agujero puede localizar su nombre. No se trata aquí de una 
niña que no respondiera por su nombre o que no pudiese nombrarse; se trata aquí del instante nombrante con estatuto de nominación (Lacan, 1974).

La paradoja en juego es la instrumentalización de un taller colectivo para dejarlo caer en el instante del acto como única manera de hacer presente la palabra que resuena y que por tocar el cuerpo conlleva efectos de separación. Pero se trata de instantes ya que de inmediato se vuelve a la escena taller que, he aquí la paradoja, nunca ha caído pero tiene que ser trascendido para que la palabra resuene.

Se podría interrogar en donde reside la fuente de la potencia de la intervención: ¿en el "no"; en el espacio dibujado que sostiene el lugar pero vaciado del llenado automático del objeto en la iteración; en el tono a partir del cual una negativa resuena invitación, reconocimiento y espera de sujeto? Lo imposible de una respuesta por una u otra delimita la paradoja en juego de la que se sale por arriba como en el laberinto: lo singular en lo colectivo.

\section{Del dispositivo maleable}

A partir de la viñeta más arriba planteada es posible considerar la lógica del dispositivo en su conjunto ya que, como que queda considerado al inicio, el taller "punto y coma" consolida una lógica que es propia de todo taller de la cigarra.

La conformación de dicho taller surge a partir de la idea de experimentar modalizaciones en la puntuación que no pasen por el sentido y considerar si eso puede alcanzar incidencia en el anudamiento. La aclaración sobre la pregunta en el origen del taller tiene su valor en virtud de que en la viñeta elegida no se pasa por este punto esencial: el intento de poner a jugar una nueva regulación de la pulsión a partir de jugar con la puntuación. A saber: normalmente en el taller aquel que coloca el punto y detiene el devenir de la frase obtiene puntaje. Así, por el solo hecho de querer ganar, muchas veces se coloca el punto en cualquier lugar y eso detiene la frase: puntuar opera detención.

El taller nace entonces como una vía, casi un laboratorio, en el que forjar un querer que eso detenga su empuje sin necesidad de pasar por la significación, sin tener que ordenarse por la regulación del Nombre del Padre. Por otro lado, por tratarse además de algunos niños con autismo, otra vertiente que interesaba se desentendía de la puntuación y buscaba adentrarse en el Uno solo en su iterar en un empuje a la articulación con otro significante para constituir una suerte de cadena que en su deriva produjese significación: "las cucarachas [ahora] miran". Se sumaba a esto la posibilidad de que, al articular con el significante encarnado en el compañero que sigue, la significación anticipada - cuando fuese posible y estuviese conservada perdía su presencia fija y abría derivas nuevas.

Tenemos entonces tres orientaciones en un mismo taller que no son complementarias pero tampoco contradictorias, y dan cuenta en un mismo juego de la articulación de posiciones que divergen en su relación al S2. 
Todo taller de la cigarra nace de una pregunta en algún analista que prefigura el armado de un juego para recorrer la pregunta a lo largo de años. Se necesita poner a prueba además su incidencia clínica.

La idea de un dispositivo maleable plantea la idea de un uso del dispositivo como materia de la que servirse para la constitución de un arreglo menos sufriente. Escribir una frase entre varios constituye la malla desde la cual entramar palabras que restan sueltas, desde la cual decir "no" valiéndose de la sintaxis a la que todos nos obligamos. Al mismo tiempo y de manera arbitraria no todos quedan obligados por la sintaxis; allí se pone en acto la lectura de la coordinación que busca hacer con esa materia, espacio a la depositación del objeto, la producción de un agujero que permita algo nuevo, la obtención de un punto o una coma que haga lugar a un respiro en el fraseo. Está entonces lo arbitrario de la sintaxis y el acto que la descompleta al permitir que en ocasiones eso no obligue y permita la entrada de una palabra a la que luego opondrá un límite.

El instante en que la niña, sin ser su turno, al escuchar nombrar por el coordinador la palabra "vacío" coloca allí su nombre es un momento de sorpresa para todos; para ella, en una palabra que la sobrepasa, para nosotros porque aún en una posición de espera nunca podremos calcular la irrupción de ese algo que siempre irrumpe inesperado y fuera de tiempo. Lo inesperado se nutre del hueco producido por haber dejado fuera lo que se reitera pero advertidos de su valor; pero solo cobra estatuto de agujero cuando en ese cavado es posible reconocerse. Cuando su nombre la sobrepase, no se tratará de una palabra que proponga para la frase sino que cuando el coordinador nombra "vacío," en la niña resuena un llamado por el que responde. Su lugar queda preservado en la frase; esto se nombra al quedar soportado en el recuadro de la frase la palabra que falta - el lugar presentifica la ausencia de una palabra que no se escribe pero se lee : "las cucarachas miran la televisión con los ojos abiertos VACIO ...."

Un dispositivo maleable pone a disposición una misma frase que se extiende, se achica, se ahueca y pasa a leerse de diversas maneras para hacer con ella un arreglo arbitrario, extemporáneo, inaudito. Con esa misma frase se despliega una modalidad imposible de la sintaxis a la medida de lo que exige la transferencia; es una sintaxis flexible con la que a veces sí, y a veces no. Y es una frase que además de palabras admite un recuadro dibujado que enmarca el lugar que ha quedado vacío, que además se lee como si allí hubiese una palabra escrita - porque es vital hacer entrar la palabra que nombre que la palabra falta -. Es maleable además porque nunca antes se había establecido dibujar en una frase y el coordinador se autoriza sin garantía mientras la frase se despliega. Se trata pues de un juego que tiene reglas para forzar, dejar caer, proponer nuevas sin previo aviso: en la táctica todo es posible cuando lo estratégico se orienta por dejar venir la sorpresa.

La frase que hace agujero no puede ser pensada como exterioridad sino que hace cuerpo en el parlêtre al permitirle hacer uso de sus agujeros desde de los cuales poner a jugar extracciones parciales, que a la vez quedan alojadas y se escriben como marcas desde la frase misma. El recuadro vacío de la frase hace posible una presencia 
de agujero con efectos palpables en aquietamiento del cuerpo.

Que el dispositivo sea maleable conlleva que con otro niño o niña esta misma frase pueda tener el valor exactamente contrario y solo se haga uso de la misma para depositar la palabra que insiste haciendo explotar la semántica. Y más, más, más. Cada quien hará el uso que se ajuste a su arreglo y también habrá aquellos para los que este taller no tenga valor alguno en la invención y se tratará de poder prestar otros escenarios en otros talleres para llevar adelante el trabajo. Un dispositivo a la medida de cada quien plantea infinitos dispositivos al mismo tiempo pero siempre, en lo que a nuestra experiencia refiere, forzando la producción de lo singular en lo colectivo.

\section{Nota}

${ }^{1}$ En entreUnos 5/ Soluciones problemáticas, el capítulo "lo singular" refiere en su totalidad a la paciente y los efectos del acto.

\section{Referencias}

Álvarez Bayón, P. (2020). El autismo, entre la lengua y la letra. Grama.

Cicchetti, M. (2021). Resonancia. entreUnos, 5. HTTPS://ENTREUNOS.COM/

Lacan,J. (1974) El seminario. Libro 22. Inédito

Lacan, J.(1975/2005). Le seminaire. Livre XXlll. Le sinthome. Seuil

Lacan, J. (1958/1987). De una cuestión preliminar a todo tratamiento posible de la psicosis. Siglo XXI.

Laurent,E. (2012). La bataille de l'autisme. De la clinique a la politique. Navarin / Le Champ Freudien.
Maleval, J-C. (2009). L'autiste et sa voix. Seuil.

Seijas, R. (2021). Cuarto. entreUnos, 5. нттPs:// ENTREUNOS.COM/

Slatopolsky,G.(2019) De la apertura del ciclo a la producción de un vacío. entreUnos, 4, 10-16. H T T P : / / E N T R E U N O S. C O M / PUBLICACIONES.PHP? ID $=5$

Slatopolsky, G. (2021). Tres puntos. entreUnos, 5. HTTPS://ENTREUNOS.COM/

Tustin, F. (1992). El cascarón protector en niños y adultos. Amorrortu. 